\title{
Effect of Cyclopoid Copepod Acanthocyclops trajani as a Supplementary Live Feed on the Growth, Survival and Fatty Acid Composition of Beluga Larvae (Huso huso)
}

\author{
Rahimeh Rahmati ${ }^{1, *} \oplus$, Abolghasem Esmaeili Fereidouni ${ }^{2}$, Naser Agh $^{3}$, Mastooreh \\ Doustdar ${ }^{4}$
}

${ }^{1}$ Caspian Sea Ecology Research Center, Sari, Iranian Fisheries Science Research Institute, Agricultural Research, Education and Extension Organization, Tehran, Iran.

${ }^{2}$ Sari Agricultural Sciences and Natural Resources University, Fisheries Faculty, Iran.

${ }^{3}$ Urmia University, Artemia \& Aquaculture Research Institute, Urmia, Iran.

${ }^{4}$ Iranian Fisheries Science Research Institute, Agricultural Research, Education and Extension Organization, Tehran, Iran.

\section{Article History}

Received Feb 10, 2020

Accepted Jun 4, 2020

First Online Jun 5, 2020

\section{Corresponding Author}

Tel.: +989117827786

E-mail: rahmati764@gmail.com

\section{Keywords}

Acanthocyclops trajani

Huso huso

Fatty acid

DHA

\begin{abstract}
This study was carried out on the effect of cyclopoid copepod Acanthocyclops trajani on beluga Larvae (Huso huso) first feeding in March 2018. The applied diets contained: the composition of Artemia naupli and Daphnia magna (A diet) and the composition of Artemia naupli, Daphnia magna and $A$. trajani (B diet). Different methods were used to prepare live feeds and the analysis of the fatty acids of live feeds and beluga larval tissues was performed according to the instruction. The results of this study indicated that the lenghth, body weight and specific growth rate average in larvae of $A$ and $B$ diets were not significantly different. In spite of the fact that $A$. trajani was significantly different in amount of $\mathrm{n}-3$ fatty acids in comparison to Artemia naupli and $D$. magna but indicated more effectivity in survival rates $(80 \%)$ of beluga larvae with these latter live feeds compound, as a supplement. Furthermore, the B diet was significantly different in essential fatty acid DHA, in comparison to A diet, So, with due attention to important effects of this fatty acid on stress resistance of larvae, the better results with the view to survival rate in this treat will be explainable.This study indicated that freshwater copepod was potential supplemental live food, specifically to increase nutritional value and survival rate of valuable fish larvae as beluga.
\end{abstract}

\section{Introduction}

The results of numerous studies showed that largescale mortality is one of the major problems in the early stages of larval development in many marine species (Turner, Tester,\&Hettler, 1985) and freshwater species (Jana \& Jana, 2003) in nursery ponds (Pillay \& Kutty, 2005). High larval mortality is usually attributed to nutritional deficiencies or imbalances in the three essential Poly Unsaturated Fatty Acids (PUFAs) in diets ( Ghost, Sen, \& Rey,2004) as well as water quality (Rice, Crowder, \& Binkowski,1987), disease and hunting (Frimpong \& LochMann, 2005). Lack of live feeds with proper nutritional value and inability to mass culture of live feed with balanced nutritional value for the first external feeding of fish larvae is a limiting factor in aquaculture (Payne \& Rippingale, 2001). Common organisms as live feeds like rotifer and Artemia sp. are deficient in Highly Unsaturated Fatty Acids (HUFA) (Rajkumar \& Kumarago, 2006). HUFA intake from diets is the only way to obtain essential fatty acids (from the $\mathrm{n}-3$ fatty acids such as EPA, DHA and ARA) in larvae because fish larvae are unable to synthesize these fatty acids from their precursors (Bell et al., 2002). In hatcheries, copepods are able to supplement the nutritional value of common live feeds. The proper nutritional profile of copepods plays an important role in the growth, health and survival of fish larvae (Aljami \& Zang, 2015). This study was carried out to investigate the effects of the Cyclopoid copepod Acanthocyclops trajani as live food at the first feeding of Huso huso larvae, one of the most valuable sturgeon species in 
Iran, commercially important fish species of the Caspian Sea and a good candidate for aquaculture (Oveisipour \& Rasco, 2011), with emphasis on the growth, survival and polyunsaturated fatty acid (PUFA) content. The high mortality rate during beluga larval rearing, which in some cases exceeds $80 \%$ (Asgari et al., 2013), is considered as one of the most serious limitations for larval rearing of this species. Beluga larvae produced in hatcheries are commonly fed on Cladocerans (Daphnia sp. and Moina sp.) and Artemia sp. at first feeding (Gisbert \& Williot, 2002) which the nutritional value of some of these live feeds is often insufficient to complete growth. Therefore, the success and development of aquaculture activity in this critically endangered species still requires some improvements in farming techniques, especially those affecting the larval stages, such as replacing whole or part of the live feed with other diets.

\section{Materials and Methods}

This study was carried out in March 2018 at the Shahid Rajaee Center for Reproduction and Rebuilding Resources of Aquatics in Sari, Mazandaran Province. Ten days after hatching the eggs (from beluga female spawners with the age of 10 to 12 years old and weight of 35 to $65 \mathrm{Kg}$ ) and at the first feeding stage, the total number of 120 beluga larvae (with the initial weight of $55 \pm 0.01 \mathrm{mg}$ and initial length of $13.7 \pm 0.1 \mathrm{~mm}$ ) were placed in containers with a capacity of 20 liters. During the larval rearing period water temperature, dissolved oxygen and $\mathrm{pH}$ were $17.7 \pm 0.2^{\circ} \mathrm{C}, 8.1 \pm 0.3 \mathrm{mg} / \mathrm{l}$ and $7.8 \pm 0.1$, respectively. The initial weight and length of the larvae were measured before the start of the experiment and at the end of the rearing period using the balance $(0.01 \mathrm{~g})$ and caliper, respectively. Feeding to larvae in different treatments of this study was performed three times a day ( $8 \mathrm{~h}$ intervals). The treatments used at this stage are presented in Table 1.

Different methods were used to prepare different live feeds at this stage. In order to prepare instar nauplii hatched from Artemia cysts, the cysts of Artemia sp. were decapsulated according to standard method and then hatched in the funnel shaped container with 100 liters water volume, salinity of $28 \mathrm{ppt}$, temperature of $28^{\circ} \mathrm{C}, 2500$ lux light intensity and intense aeration (Gomez-Gil, Herrera, Aberu, \& Roque,1998). After 24 hours, the instar I nauplii hatched from Artemia cysts were prepared, siphoned with a $120-\mu \mathrm{m}$ net and used for the feeding of larvae. To prepare the copepodid of $A$. trajani, all facilities for mass production were provided in the live feed hall of the Shahid Rajaee Center in the five funnel shaped containers with 100 liters water volume. The mass production techniques were used and to feed $A$. trajani, a mixture of dried algae Scenedesmus obliquus and Spirulina maxima $(4.18 \mu \mathrm{g} / \mathrm{ml}$ water) were used with continuous aeration at the bottom of the tank and temperature of $22^{\circ} \mathrm{C}$ (using the aquarium heaters) as well as the $12 / 12$ light cycle (light/dark cycle) in indoor conditions. Water exchange in these containers was performed once every 3 days and the copepods (50\% copepodid 1 and rarely $2+50 \%$ nauplii) were harvested using the plankton nets (nets with the mesh size of $500 \mu \mathrm{m}$ and $100 \mu \mathrm{m})$. Finally, they were used to feed the larvae (Rahmati, 2018). For the preparation of cladoceran Daphnia magna, their daily harvest was carried out from Daphnia magna rearing earthen ponds at the Shahid Rajaee Center using the plankton nets with the mesh size of $500 \mu \mathrm{m}$. The wastes were then removed from the specimens and after washing the specimens, they were used for feeding the larvae.

\section{Test Plan}

Two treatments (each with three replications) were used for the test. Experiments were performed in 6 containers with 20 liters volume. After adaptation of beluga larvae to the water temperature of the tank $\left(18^{\circ} \mathrm{C}\right), 20$ beluga larvae with the average weight and length of $55 \pm 0.01 \mathrm{mg}$ and $13.7 \pm 0.1 \mathrm{~mm}$, respectively were distributed in each container. $50 \%$ of the volume of larval rearing tanks was replaced daily, and the litter and feces residues were removed using a siphon. Duration of this stage was 14 days. At the end of the period, the final length and weight of larvae were measured in different replicates of each treatment. The larval growth rate and specific growth rate (SGR) of the body length and weight of larvae (in percent per day) were calculated using the following equations (Hopkins, 1992).

$$
\begin{gathered}
S G R=100 \times\left(L_{n} S L_{f}-L n S L_{i}\right) / t_{2}-t_{1} \text { Whereas; } \\
S L_{f}=\text { Final length in } m m \\
S L_{i}=\text { Initial length in } m m \\
t_{2}=\text { The length of the early larval rearing period } \\
t_{2}=\text { The length of the final larval rearing period } \\
S G R=100 \times\left(\text { Ln } W_{f}-L n W_{i}\right) / t_{2}-t_{1} \text { Whereas; } \\
W_{f}=\text { Final weight in } g \\
W_{i}=\text { Initial weight in } g
\end{gathered}
$$

In order to calculate larval survival rate (in percentage), larval mortality trend was recorded daily in each rearing container and finally the survival rate was calculated for each treatment (Bilton \& Robins, 1973).

Larval survival rate (in percentage); Number of remaining healthy larvae / Total number of primary larvae $\times 100$

The following equations were used to calculate the percentages of larval length gain and larval weight gain percentages as well as larval status index (Hung, Lutez, \& Storebakken, 1989; Hung \& Lutez, 1987);

$$
\begin{gathered}
W(\%)=W_{f}-W_{i} / W_{i} \times 100 \\
L(\%)=L_{f}-L_{i} / L_{i} \times 100 \\
C F=W_{f} / a L^{b} \times 100
\end{gathered}
$$


Table 1. Feeding protocol of 10-day-old beluga larvae (at the first feeding stage) with a variety of live feeds during larval culture

\begin{tabular}{lc}
\hline Treatment & Live feeds (ind $/ \mathrm{ml}$ ) \\
\hline A diet & Artemia nauplii (0.3) + Daphnia magna (0.3) \\
B diet & Artemia nauplii (0.1) + Daphnia magna $(0.2)+$ Copepods (0.3) \\
\hline
\end{tabular}

Also, ten beluga larvae from each treatment replication were stored in the freezer at $-80^{\circ} \mathrm{C}$ for the analysis of fatty acids. Analysis of the fatty acids of larval tissues was performed according to the instruction (Miquel \& Browse, 1992).

\section{Statistical Analysis}

Results of biometric measurements and the amounts of fatty acids of beluga larvae were presented as mean \pm standard error. Statistical analysis was performed using SPSS software (Version 22) (SPSS, Chicago, IL, USA). Comparison of the amounts of fatty acids in two treatments was performed using one-way ANOVA (Analysis of variance) at the significant level of $5 \%$. When the results of the main analysis were significantly different, the Post hoc multiple comparison tests using LSD test were carried out. Normality and homogeneity of variance and independence of errors were tested for performing the analysis of variance.

\section{Results}

\section{Growth Parameters in Beluga Larvae in Different Treatments}

The results of growth parameters of beluga larvae in different treatments are presented in Table 2. Statistical analysis on specific growth rate of the body length and weight of beluga larvae during the larval culture revealed that there was no significant difference $(P>0.05)$ between two treatments, whereas the results of statistical analysis on survival rate in different treatments indicated that there was a significant difference between the $A$ diet treatment and the $B$ diet treatment $(P<0.05)$ (Figure 1$)$.

\section{Fatty Acid Composition in the Body of Beluga larvae Fed in Different Treatments}

Fatty acid profiles in live feeds as well as the body of beluga larvae in 2 treatments are presented in Tables 3 and 4.

\section{Saturated Fatty Acids}

Five types of saturated fatty acids were identified in the body of beluga larvae fed in different treatments (Table 4). Among various types of saturated fatty acids, only the amounts of C20:0 (2.95 $\pm 0.02 \%)$ were significantly different between the treatments $(P<0.05)$.

\section{Monounsaturated Fatty Acids}

Six types of monounsaturated fatty acids were identified in the body of beluga larvae fed in different treatments (Table 4). The statistical analysis results showed that the amounts of $\mathrm{C} 16: 1 \mathrm{n}-7$ and $\mathrm{C} 18: 1 \mathrm{n}-7$ fatty acids were significantly different between the treatments $(P<0.05)$.

\section{Long Chain Unsaturated Fatty Acids (PUFA and HUFA)}

Seven types of long chain unsaturated fatty acids were identified in the body of beluga larvae fed in different treatments. The average amounts of arachidonic acid and eicosapentaenoic acid (EPA) were significantly different between the treatments $(P<0.05)$. Among various types of long chain unsaturated and essential fatty acids, the amounts of DHA were significantly different between the treatments $(P<0.05)$.

\section{Discussion}

Previous studies showed that the use of freshwater copepods (as a supplementary live feed) can improve the survival and growth rate of many freshwater fish larvae (Sipauba-Tavares \& Pereira, 2008; Drillett, Jorgensen, Sorensen, Ramlov, \& Hansen, 2006; Camus \& Zeng, 2009). The results of using of $A$. trajani for feeding the beluga larvae in the present study showed that the average amounts of final length and final weight of beluga larvae in the A diet (Artemia nauplii + Daphnia magna) and B diet (Artemia nauplii + Daphnia magna + Copepods) were not significantly different $(P>0.05)$. The amounts of specific growth rate were not significantly different between the treatments $(P>0.05)$. The results showed that larvae fed on $B$ diet had significantly higher survival rate $(80 \%)$ compared to $A \operatorname{diet}(55 \%)(P<0.05)$. Most larval mortality occurs during beluga fish growth in two different stages, first between hatching and beginning of external feeding (when the larvae are undergoing a severe process of organ formation) (Dettlaff, Ginsburg, \& Schmalhausen, 1993) and then with the weaning stage of beluga larvae (Asgari et al., 2013). These two stages are the most sensitive stages of larval culture that should be considered to reduce mortality. According to the results of the present study, the inclusion of copepods as a supplement with other conventional live feeds for larval culture resulted in a significant improvement in larval survival. Previous research showed that changes in lipase activity in beluga larvae may be more related to changes in food quality and quantity than to the ability of fish to digest. Also, a 
Table 2. Growth parameters of beluga larvae in treatments

\begin{tabular}{lcc}
\hline Growth parameters & Artemia nauplii + Daphnia magna & Artemia nauplii + Daphnia magna + Copepods \\
\hline Initial weight $(\mathrm{g})$ & $55 \pm 1.6$ & $55 \pm 1.6$ \\
Final weight $(\mathrm{g})$ & $589 \pm 101^{\mathrm{a}}$ & $567 \pm 93^{\mathrm{a}}$ \\
Weight gain (\%) & $968 \pm 183^{\mathrm{a}}$ & $928 \pm 16^{\mathrm{a}}$ \\
Specific growth rate of body weight & $16.81 \pm 1.34^{\mathrm{a}}$ & $16.54 \pm 1.23^{\mathrm{a}}$ \\
Initial length (mm) & $13.7 \pm 1.12$ & $13.7 \pm 1.12$ \\
Final length (mm) & $41 \pm 4^{\mathrm{a}}$ & $41 \pm 3^{\mathrm{a}}$ \\
Increase of body length (\%) & $196 \pm 33^{\mathrm{a}}$ & $201 \pm 23^{\mathrm{a}}$ \\
Specific growth rate of body length & $7.71 \pm 0.83^{\mathrm{a}}$ & $7.84 \pm 0.56^{\mathrm{a}}$ \\
Larval status index & $1.33 \pm 0.10^{\mathrm{a}}$ & $1.25 \pm 0.18^{\mathrm{a}}$ \\
Survival rate (\%) & $55 \pm 5^{\mathrm{b}}$ & $80 \pm 10^{\mathrm{a}}$ \\
\hline
\end{tabular}

Figure 1. Survival rate of beluga larvae in different diets.

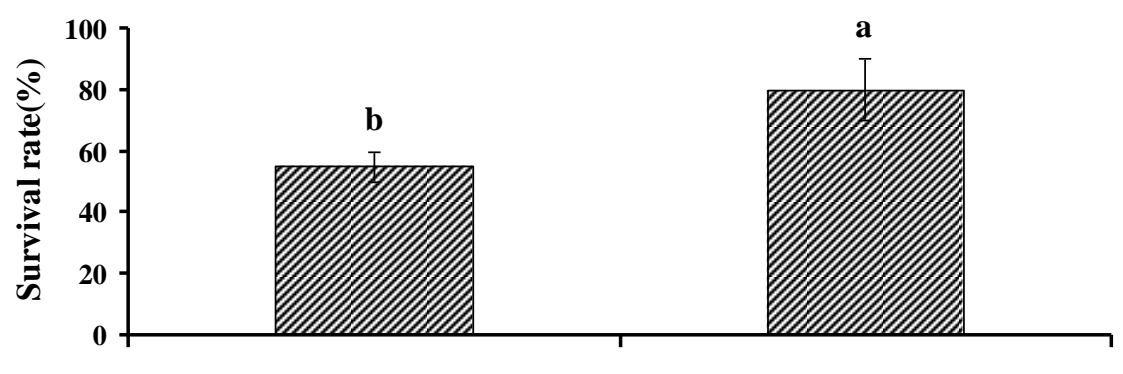

A Diet

B Diet

slight increase in dietary fat content of up to $4 \%$ during the weaning stage may increase lipase production in larvae (Rønnestad I. \& Morais, 2007; Ronstad et al., 2013). Results from previous studies showed that the addition of copepods as a live feed can increase the growth and survival of fish larvae at first feeding compared to diets containing only conventional live feeds (such as rotifers and Artemia nauplii) (Watanabe, Kitajima, \& Fujita, 1983; Shields et al., 1999; Payne \& Rippingale, 2001). For example, feeding the larvae of the catfish Clarias gariepinus using freshwater cyclopoid copepods showed that the larvae fed with a combination of freshwater cyclopoid copepods and Artemia nauplii had better growth $(9.1 \mathrm{~mm})$ than the larvae fed with a diet containing only Artemia nauplii (8.8 mm) (Chepkwemoi et al., 2013). In the study of Farhadian, Kharamannia, Mahboobi Soofiani, and Ebrahimi (2014), the freshwater fish larvae of Pterophyllum scalare fed with a combination of cyclopoid copepod Eucyclops serrulatus and cladocer Ceriodaphnia quadrangular had higher specific growth rates (23.2 per day) in comparison to feeding on a pure diet (19.2 per day) in the first week of larval culture. This trend continued in the second and third weeks. Also, the survival rate of fish larvae was 5.5\% higher in larvae fed with a combined treatment with copepods. Growth and survival rates in Lates calcarifer larvae that fed with a combined treatment containing cyclopoid copepod Cyclopina kasignete were improved and the growth rate of larvae reached from $4.93 \%$ per day in the treatment containing rotifers and Artemia nauplii to $6.35 \%$ per day in the treatment containing rotifers, Artemia nauplii and copepods. The survival rate of larvae also increased from $42.60 \%$ in the treatment containing rotifers and Artemia nauplii to $64.20 \%$ in the treatment containing rotifers, Artemia nauplii and copepods (Rasdi, 2015). In a study by Zeng, Shao, Ricketts, and Moorhead (2018) these organisms, at densities of 2 organisms per $\mathrm{ml}$ in the treatment containing rotifers, increased the survival of ornamental larvae Synchiropus splendidus from less than $6 \%$ in the treatment containing only rotifers to $50 \%$. These organisms significantly increased larval growth rate from 1.96 to $5.48 \%$ per day. In another study Barroso, Carvalho, Antoniassi, and Cerqueira (2013) in using copepod Acartia tonsa as the first live feed for feeding the larvae of Centropomus parallelus showed that the combined treatment containing copepod A. tonsa and Brachionus rotundiformis significantly increased the survival rate of larvae from $5 \%$ to $16 \%$ as well as the mean larval weight from 0.71 $\mathrm{mg}$ to $0.84 \mathrm{mg}$. In edible and commercially valuable fish, Toledo, Golez, Doi, and Ohno (1999) reported that the growth and survival of larvae of orange - spotted grouper (Epinephelus coioides) significantly increased when the larvae fed with a combined treatment containing Brachionus rotundiformis and combination of nauplii of some copepods (Acartia tsuensus, Pseudodiaptis sp. and Oithona sp.) at densities of 0.1 organism per ml. Similarly, the survival rates of larvae of northern red snapper (Lutjanus campechanus) that fed with a diet containing nauplii of Parvocalanus sp. were significantly increased as compared to the survival rates of larvae fed with the control diet. The larval size was also larger on the seventh day after the yolk sac was 
Table 3. The amounts of fatty acids (\%) in live feeds used in the present study

\begin{tabular}{|c|c|c|c|}
\hline Fatty acid & Artemia nauplii & Daphnia magna & Acanthocyclops trajani \\
\hline \multicolumn{4}{|l|}{ Saturated } \\
\hline C14:0 & $0.76 \pm 0.03^{b}$ & $5.64 \pm 0.15^{a}$ & $0.92 \pm 0.42^{b}$ \\
\hline C16:0 & $14.58 \pm 0.66^{b}$ & $24.13 \pm 0.65$ a & $10.79 \pm 0.67 \mathrm{c}$ \\
\hline C18:0 & $34.57 \pm 1.57$ a & $14.71 \pm 0.39 b$ & $5.91 \pm 0.47^{c}$ \\
\hline $\mathrm{C} 20: 0$ & $1.10 \pm 0.05^{b}$ & $2.32 \pm 0.06^{b}$ & $6.31 \pm 1.82$ a \\
\hline C22:0 & $0.71 \pm 0.03^{b}$ & $0.69 \pm 0.02^{b}$ & $2.31 \pm 0.23 \mathrm{a}$ \\
\hline $\mathrm{C} 24: 0$ & - & $1.05 \pm 0.03$ & $8.12 \pm 4.71$ \\
\hline Sum & 51.72 & 48.54 & 58.36 \\
\hline \multicolumn{4}{|l|}{ Monounsaturated } \\
\hline C14:1 n5 & $0.22 \pm 0.01^{c}$ & $1.31 \pm 0.04^{b}$ & $11.62 \pm 1.61^{a}$ \\
\hline C16:1 n7 & $3.66 \pm 0.17^{c}$ & $8.89 \pm 0.24^{b}$ & $16.02 \pm 1.85^{a}$ \\
\hline C18:1 n9 & $5.76 \pm 0.26^{b}$ & $15.40 \pm 0.41^{a}$ & $3.26 \pm 1.22 \mathrm{~b}$ \\
\hline $\mathrm{C} 18: 1 \mathrm{n} 7$ & - & $2.38 \pm 0.06^{a}$ & $1.47 \pm 0.52^{b}$ \\
\hline C20:1 n9 & $0.27 \pm 0.01 \mathrm{~b}$ & $0.56 \pm 0.02{ }^{a}$ & $0.08 \pm 0.08^{b}$ \\
\hline $\mathrm{C} 22: 1 \mathrm{n} 9$ & - & $0.13 \pm 0.00^{b}$ & $4.50 \pm 2.36^{a}$ \\
\hline C24:1 n9 & - & - & $10.29 \pm 4.37$ \\
\hline Sum & 9.91 & 28.67 & 47.24 \\
\hline \multicolumn{4}{|l|}{ Polyunsaturated } \\
\hline $\mathrm{C} 18: 2 \mathrm{n} 6 \mathrm{CIS}$ & $18.06 \pm 0.82^{a}$ & $5.09 \pm 0.14^{b}$ & $0.89 \pm 0.31^{c}$ \\
\hline C18:3 n3 $\left(\mathrm{ALA}^{1}\right)$ & $3.39 \pm 0.15$ & $1.29 \pm 0.03$ & $3.88 \pm 1.38$ \\
\hline $\mathrm{C} 20: 2 \mathrm{n} 6$ & $1.04 \pm 0.05$ & $2.07 \pm 0.06$ & $1.80 \pm 0.45$ \\
\hline C20:4 n6 (ARA $\left.{ }^{1}\right)$ & $1.98 \pm 0.09$ & $2.04 \pm 0.05$ & $2.86 \pm 1.47$ \\
\hline $\mathrm{C} 20: 3 \mathrm{n} 3$ & $0.22 \pm 0.01 \mathrm{~b}$ & $0.06 \pm 0.00^{b}$ & $9.91 \pm 6.88$ a \\
\hline C20:5 n3 (EPA $\left.{ }^{1}\right)$ & $3.51 \pm 0.16$ & $4.09 \pm 0.11$ & $3.51 \pm 2.65$ \\
\hline $\mathrm{C} 22: 6 \mathrm{n} 3\left(\mathrm{DHA}^{1}\right)$ & $0.97 \pm 0.04^{c}$ & $3.72 \pm 0.10^{b}$ & $4.81 \pm 0.40^{a}$ \\
\hline Sum & 29.17 & 18.36 & 27.66 \\
\hline$n-3$ & $8.08 \pm 0.37^{b}$ & $9.16 \pm 0.25^{b}$ & $22.10 \pm 6.01^{\text {a }}$ \\
\hline$n-6$ & $21.09 \pm 0.96^{a}$ & $9.20 \pm 0.25^{b}$ & $5.55 \pm 0.71^{b}$ \\
\hline
\end{tabular}

Table 4. The amounts of fatty acids (\%) in the body of beluga larvae fed in 2 treatments during the larval culture

\begin{tabular}{|c|c|c|}
\hline Fatty acid & Artemia nauplii + Daphnia magna & Artemia nauplii + Daphnia magna + Copepod \\
\hline C14:0 & $0.63 \pm 0.45$ & $0.06 \pm 0.02$ \\
\hline $\mathrm{C} 16: 0$ & $13.65 \pm 1.09$ & $13.32 \pm 0.38$ \\
\hline ¿ & $4.21 \pm 0.39$ & $4.25 \pm 0.27$ \\
\hline$\stackrel{\frac{\pi}{J}}{J} \mathrm{C} 20: 0$ & $2.95 \pm 0.02$ & - \\
\hline$\stackrel{\vec{D}}{\sim} \mathrm{N} C 22: 0$ & - & $0.72 \pm 0.29$ \\
\hline$\sim \mathrm{c} 24: 0$ & - & - \\
\hline Sum & 21.44 & 18.35 \\
\hline C14:1 n5 & $2.44 \pm 0.73$ & $1.55 \pm 0.16$ \\
\hline C C16:1 n7 & $4.08 \pm 0.03$ a & $3.32 \pm 0.02 b$ \\
\hline$\underset{\pi}{\stackrel{0}{0} \mathrm{C}} 18: 1 \mathrm{n} 9$ & $6.50 \pm 0.32^{a}$ & $6.71 \pm 0.24{ }^{\text {a }}$ \\
\hline C18:1 n7 & $4.43 \pm 0.09$ a & $3.56 \pm 0.12 b$ \\
\hline ڤ̆ $\mathrm{C} 20: 1 \mathrm{n} 9$ & - & $1.16 \pm 0.07$ \\
\hline 등 C22:1 n9 & - & - \\
\hline$\sum \mathrm{C} 24: 1 \mathrm{n} 9$ & $1.09 \pm 1.09$ & $2.04 \pm 0.10$ \\
\hline Sum & 18.54 & 18.34 \\
\hline $\mathrm{C} 18: 2 \mathrm{n} 6 \mathrm{CIS}$ & $2.54 \pm 0.03^{a}$ & $2.43 \pm 0.01^{a}$ \\
\hline 하 C18:3 n3 (ALA) & $5.54 \pm 2.32 \mathrm{a}$ & $2.81 \pm 0.05^{a}$ \\
\hline 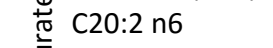 & - & $0.22 \pm 0.02$ \\
\hline 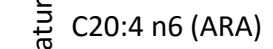 & $3.65 \pm 0.19$ a & $4.72 \pm 0.13^{b}$ \\
\hline 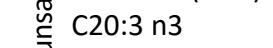 & $4.04 \pm 2.00$ & $0.95 \pm 0.49$ \\
\hline 三 $\mathrm{C} 20: 5 \mathrm{n} 3$ (EPA) & $19.32 \pm 0.37^{a}$ & $15.10 \pm 0.40^{b}$ \\
\hline ¿ $C 22: 6$ n3 (DHA) & $16.72 \pm 0.00^{b}$ & $21.47 \pm 0.47$ a \\
\hline Sum & 51.81 & 47.70 \\
\hline$n-3 / n-6$ & $7.38 \pm 0.83^{a}$ & $5.48 \pm 0.02^{a}$ \\
\hline
\end{tabular}

All values are presented as mean \pm standard error. $n=3$. The sign (-) indicates a very low amount of fatty acids. Different letters indicate a significant difference between the treatments. 
absorbed than that of the control treatment (Shields et al., 2005). In studies on fatty acid composition of beluga larvae, PUFA fatty acids showed a higher percentage compared to those of SFA and MUFA fatty acids. The predominance of PUFA over MUFA in the diets of this study has been consistent with previous research (Wiegand, 1996; Chepkwemoi et al., 2013). The preferential catabolism of MUFA has been demonstrated in a large number of species of fish compared to the preferential retention of essential fatty acids by larvae (Wiegand, 1996). In the study of essential fatty acids in beluga larvae tissues, ARA and EPA fatty acids showed the highest values in the A diet and they were significantly different. In a study by Chepkwemoi et al. (2013), the amount of EPA fatty acid in the larvae of Asian sea bass (Lates calcarifer) fed with Artemia was higher (3.71\%) than in larvae fed with copepods. Also, in the study by Rajkumar and Kumaragura (2006), the amount of EPA fatty acid in the larvae fed with Artemia (9.98\%) was higher than in larvae fed with copepods (8.17\%). The most important essential fatty acid, DHA, in beluga larvae tissues with the amount of $21.47 \%$ was observed in B diet. The amount of DHA fatty acid in these larvae was significantly different as compared to A diet. In the research by Rasdi (2015) study, the amount of DHA (12.30\%) in the larvae of Asian sea bass (Lates calcarifer) fed with a combination of rotifers, Artemia nauplii and copepods was higher as compared to the amount of DHA fatty acid (12\%) in the larvae fed with rotifers and copepods. In the study by Rajkumar and Kumaragura (2006), the amount of DHA fatty acid increased by 5 -fold in the treatment of fish larvae fed with copepods. Chepkwemoi et al. (2013) found that the composition of essential fatty acids in fish larvae fed with the combination of Artemia nauplii and cyclopoid copepods was better than the control treatment because the contents of EPA and ALA fatty acids were higher in larvae fed with Artemia nauplii whereas the content of DHA was higher in larvae fed on pure copepods. Therefore, the combined treatment had a more balanced content of essential fatty acids. Fatty acid analysis of Artemia nauplii, Daphnia magna and $A$. trajani showed that these three organisms were not significantly different in the amount of essential fatty acids of ALA, ARA and EPA. The amount of DHA was very low in Artemia nauplii and there was a significant difference among these live feeds. The amounts of C20:3 n-3 and C22:6 n-3 in cladoceran Daphnia magna were significantly different as compared to A. trajani. The amounts of $n-3$ fatty acids (22.10\%) and n-3 / n- 6 fatty acids (4.19\%) in A. trajani were significantly higher than those of the others. The larvae fed on the $B$ diet showed significantly higher survival rate than the A diet, although there were no significant differences in the average amounts of length, weight and growth rate. As previously mentioned in the study of essential fatty acid profiles in beluga larvae, the treatment with copepods was only significantly different in the amount of DHA fatty acid as from another treatment. Therefore, the high survival rate in this treatment indicated the high importance of DHA fatty acid in the survival of beluga larvae. DHA fatty acid has important effects on larval resistance to stress. The DHA fatty acid content of $A$. trajani was higher than Artemia nauplii so larvae fed on it, showed better results in terms of survival, growth and stress resistance (Fujita, 1979), because DHA plays an important role in the structure of neuronal and retinal cells. The higher DHA content can increase larval visual performance and improve larval response to feeding and ultimately higher survival rate (Chepkwemoi et al., 2013). Studies by Evjemo, Reitan, and Olsen (2003) showed that the essential fatty acids, especially DHA, should be provided by the diet and cannot be synthesized in the body of fish larvae. Higher levels of DHA (21.47\%) in the larvae fed with B diet were due to the high percentage of this essential fatty acid in Daphnia magna $(3.72 \%)$ and in particular in A. trajani $(4.81 \%)$, which greatly influenced on the survival rate of beluga larvae. Such this trend was previously expressed in Atlantic halibut, so that the high percentages of EPA and DHA in the copepod Temora longicornis resulted in the higher percentages of these essential fatty acids in the larvae of Atlantic halibut (Hippoglossus hippoglossus) compared to larvae fed with Artemia franciscana (Evjemo et al., 2003). In general, fish larvae at their first feeding need fatty acids and amino acids as major sources of energy (Park, Puvanendran, Kellett, Parrish, \& Brown, 2006). The newly hatched larvae (containing yolk sac) have high levels of energy storage, but nutritional value of their tissue declines rapidly after hatching (Buentello et al., 2011). Fish larvae are plankton eaters and choose the appropriate live feed during the period after the yolk sack absorbing to obtain the proper energy and nutrients. Therefore, the composition of live feed and their quality are of great importance for the growth and development of fish larvae (Ma, Qin, Hutchinson, \& Chen, 2013). In a study by Farhadian et al. (2014), food selection index by the larvae of Pterophyllum scalare decreased with increasing age for the consumption of copepodids Eucyclops serrulatus. The reason for the greater tendency for consumption of copepods in the first feeding week was probably the low size and weight of copepods nauplii and the low larval hunting ability. In most aquaculture studies, the effects of marine water copepods on feeding the marine larvae in hatcheries were investigated. In the present study it was found that freshwater copepods could also be used as a supplementary live feed, especially for improving nutritional value and increasing the survival of valuable fish larvae such as beluga (Huso huso) larvae.

\section{Conclusion}

Therefore, considering the positive results of this study in increasing the essential fatty acid content such 
as DHA and subsequently to significantly increase the survival rate of beluga fish larvae and the difficulties in cultivating freshwater copepods especially in terms of time-consuming generation and population growth as well as lower productivity compared to conventional live feeds, it is recommended that copepods be added to other live feeds shortly after the yolk sack absorbing as a supplementary live feed.

\section{Acknowledgement}

The writing of this research article was supported by Sari Agricultural Sciences and Natural Resources University and Center of Reproduction and Rebuilding Resources of Aquatics in Iran, Mazandaran, Sari.

\section{References}

Aljami, F., \& Zeng, C. (2015). Evaluation of microalgal diets for the intensive cultivation of the tropical calanoid copepod, Parvocalanus crassirostris. Aquaculture Research, 46 (5), 1025-1038. https://doi.org/10.1111/are.12254

Asgari, R., Rafiee, G., Eagdari, S., Noori, F., Agh, N., Poorbagher, H., \& Gisbert, E. (2013). Ontogeny of the digestive enzyme activities in hatchery produced Beluga (Huso huso). Aquaculture, 416(416-417), 33-40. https://doi.org/10.1016/j.aquaculture.2013.08.014

Barroso, M.V., de Carvalho, C.V.A., Antoniassi, R., \& Cerqueira, V.R. (2013). Use of the copepod Acartia tonsa as the first live food for larvae of the fat snook Centropomus parallelus. Aquaculture, 388 (1), 153-158. https://doi.org/10.1016/j.aquaculture.2013.01.022

Bell, J.G., Henderson, R.J., Tocher, D.R., McGhee, F., Dick, J.R., Porter, A., Smullen, R.P. \& Sargent, J.R. (2002). Substituting fish oil with crude palm oil in the diet of Atlantic salmon (Salmo salar) affects muscle fatty acid composition and hepatic fatty acid metabolism. The Journal of Nutrition, 132(2), 222-230. https://doi.10.1093/jn/132.2.222

Bilton, H.T., \& Robins, G.L. (1973). The effects of starvation and subsequent feeding on survival and growth of fulton channel sockeye salmon fry (Onchorhynchus nerka) fry. Canadian Journal of Fisheries and Aquatic Sciences, 30(1), 1-5. https://doi.org/10.1139/f73-001

Buentello, J.A., Pohlenz, C., Margulies, D., Scholey, V.P., Wexler, J.B., Tovar-Ramírez, D., Neill, W.H., HinojosaBaltazar, P., \& Gatlin, D.M. (2011). A preliminary study of digestive enzyme activities and amino acid composition of early juvenile yellowfin tuna (Thunnus albacares). Aquaculture, 312(1-4), 205-211. https://doi.org/10.1016/j.aquaculture.2010.12.027

Camus, T., \& Zeng, C. (2009). The effects of stocking density on egg production and hatching success, cannibalism rate, sex ratio and population growth of the tropical calanoid copepod Acartia sinjiensis. Aquaculture, 287(1-2), 145151. https://doi.org/10.1016/j.aquaculture.2008.10.005

Chepkwemoi, P., Bwanika, G.N., Kwetegyeka, J., Mbahizireki, G., Ndawula, L., \& Izaara, A.A. (2013). Fatty acid profiles and growth of African catfish larvae fed on freshwater cyclopoid copepods and artemia as live starter feed. International Journal of Aquaculture, 3(22), 411-419. https://doi. 10.5376/ija.2013.03.0022
Dettlaff, T.A., Ginsburg, A.S., \& Schmalhausen, O.I. (1993). Sturgeon Fishes: Developmental Biology and Aquaculture. Springer-Verlag Ed, Berlin, Germany., 299 pp.

Drillet, G., Jorgensen, N.O.G., Sorensen, T.F., Ramlov, H., \& Hansen, B.W. (2006). Biochemical and technical observations supporting the use of copepods as live feed organisms in marine larviculture. Aquaculture Research, 37(8), 756-772. https://doi.org/10.1111/j.13652109.2006.01489.x

Evjemo, J.O., Reitan, K.I., \& Olsen, Y. (2003). Copepods as live food organisms in the larval rearing of halibut (Hippoglossus hippoglossus) with special emphasis on the nutritional value. Aquaculture, 227(1-4),191-210. https://doi.org/10.1016/S0044-8486(03)00503-9

Farhadian, O., Kharamannia, R., Mahboobi soofiani, N., \& Ebrahimi, E. (2014). Larval feeding behaviour of angel fish Pterophyllum scalare (Cichlidae) fed copepod Eucyclops serrulatus and cladoceran Ceriodaphnia quadrangular. Aquaculture Research, 45(7), 1212-1223. https://doi.org/10.1111/are.12065

Frimpong, E.A., \& Lochmann, S.E. (2005). Mortality of fish larvae exposed to varying concentrations of cyclopoid copepods. North American Journal of Aquaculture, 67(1), 66-71. https://doi/abs/10.1577/FA03-066.1

Fujita, S. (1979). Culture of red sea bream, Pagrus major and its food. Special Publication Emergency Medical Services (EMS), 14, 183-197.

Ghost, K., Sen, S.K., \& Ray, A.K. (2004). Growth and survival of Rohu, Labeo rohita (Hamilton, 1822) spawn fed diets fermented with intestinal bacterium, Bacillus circulans. Acta Ichthyologica et Piscatoria, 34(2),155-165. https://doi/10.3750/AIP2004.34.2.04

Gisbert, E., \& Williot, P. (2002). Advances in the larval rearing of Siberian sturgeon. Journal of Fish Biology, 60(5), 1071 1077. https://doi.org/10.1111/j.1095-8649.2002.tb01705.x

Gomez-Gil, B., Herrera-Vega, M.A., Aberu-Grobis, F.A., \& Roque, A. (1998). Bioencapsulation of two different vibrio species in nauplii of the brine shrimp (Artemia fransiscana). Applied Enviromental Microbiology, 64 (6), 2318-2322.

Hopkins, K.D. (1992). Reporting Fish Growth: A Review of the Basics. Journal of the World Aquaculture Society, 23(3), 173-179. https://doi.org/10.1111/j.1749-7345.1992.tb00766.x

Hung, S.S.O., \& Lutes, P.B. (1987). Optimum feeding rate of hatchery produced juvenile white sturgeon (Acipenser transmontanus). Aquaculture, 65(3-4), 307-317. https://doi.org/10.1016/0044-8486(87)90243-2

Hung, S.S.O., Lutes, P.B., \& Storebakken, T. (1989). Growth and feed efficiency of white sturgeon (Acipenser transmontanus) sub yearling at different feeding rates. Aquaculture, 8(1-2), 147-153. https://doi.org/10.1016/0044-8486(89)90280-9

Jana, B.B., \& Jana, S. (2003). The potential and sustainability of aquaculture in India. Journal of Applied Aquaculture, 13(3-4), 283-316. https://doi.org/10.1300/J028v13n03_05

Ma, Z., Qin, J.G., Hutchinson, W., \& Chen, B.N. (2013). Food consumption and selectivity by larval yellowtail kingfish Seriola lalandi cultured at different live feed densities. Aquaculture Nutrition, 19(4), 523-534. https://doi.org/10.1111/anu.12004 
Miquel, M., \& Browse, J. (1992). Arabidopsis mutants deficient in polyunsaturated fatty acid synthesis (biochemical and genetic characterization of a plant oleoylphosphatidylcholine desaturase. The Journal of Biological Chemistry, 267(3),1502-1509.

Oveisipour, M., \& Rasco, B. (2011). Fatty acid and amino acid profiles of domestic and wild beluga (Huso huso) roe and impact on fertilization ratio. Journal Aquaculture Research and Development, 2(3),1-14. https://doi: 10.4172/2155-9546.1000113

Park, H.G., Puvanendran, V., Kellett, A., Parrish, C.C., \& Brown, J.A. (2006). Effect of enriched rotifers on growth, survival, and composition of larval Atlantic cod (Gadus morhua). ICES Journal of Marine Science: Journal du Conseil. 63(2), 285-295. https://doi.org/10.1016/j.icesjms.2005.10.011

Payne, M.F., \& Rippingale, R.J. (2001). Effects of salinity, cold storage and enrichment on the calanoid copepod Gladioferens imparipes. Aquaculture, 201(3-4), 251-262. https://doi.org/10.1016/S0044-8486(01)00609-3

Pillay, T.V.R., \& Kutty, M.N. (2005). Aquaculture: Principles and practices. Wiley-Blackwell. $624 \mathrm{pp}$.

Rahmati, R. (2018). The effect of food diet type on production density and nutritional value improvement of cyclopoid copepod Acanthocyclops trajani and its role on the first feeding of Huso huso larvae. (PhD Thesis). Agricultural Sciences and Natural Resources University. Sari, Mazandaran, Iran.

Rajkumar, K.P., \& Kumaraguru, V. (2006). Suitability of the copepod, Acartia clausi as a live feed for Seabass larvae (Lates calcarifer Bloch): Compared to traditional live food organisms with special emphasis on the nutritional value. Aquaculture, 261(2), 649-658. https://doi:10.1016/j.aquaculture.2006.08.043

Rasdi, N.W., Qin, J.G., \& Li, Y. (2015). Effects of dietary microalgae on fatty acids and digestive enzymes in copepod Cyclopina kasignete, a potential live food for fish larvae. Aquaculture Research, 47(10), 32543264. https://doi.org/10.1111/are.12778

Rice, J.A., Crowder, L.B., \& Binkowski, F.P. (1987). Evaluating potential sources ofmortality for larval bloater (Coregonus hoyi): starvation and vulnerability to predation. Canadian Journal of Fisheries and Aquatic Sciences, 44(2),467-472. https://doi:10.1139/f87-055

Rønnestad, I., \& Morais, S. (2007). Digestion. In: Fin, R.N., Kapoor, B.G. (Eds.), Fish Larval Physiology. Science Publishers, Enfield. 201-262.
Rønnestad, I., Yúfera, M., Ueberschär, B., Ribeiro, L., Sæle, Ø., \& Boglione, C. (2013). Feeding behaviour and digestive physiology in larval fish: current knowledge and gaps and bottlenecks in research. Reviews in Aquaculture, 5(s1), 559-598. https://doi.org/10.1111/raq.12010

Shields, R.J., Bell, J.G., Luizi, F.S., Gara, B., Bromage, N.R., \& Sargent, J.R. (1999). Natural copepods are superior to enriched Artemia nauplii as feed for halibut larvae (Hippoglossus hippoglossus) in terms of survival, pigmentation and retinal morphology: relation to dietary essential fatty acids. The Journal of Nutrition. 129(6), 1186-1194. https://doi:10.1093/jn/129.6.1186

Shields, R.J., Kotani, T., Molnar, A., Marion, K., Kobashigawa, J., \& Tang, L. (2005). Intensive culture of a Calanoid copepod, Pavovalanus sp., as prey for small sub-tropical marine fish larvae. (pp. 209-223). Copepods in Aquaculture., $269 \mathrm{pp}$.

Sipauba-Tavares, L., \& Pereira, A. (2008). Large scale laboratory cultures of Ankistrodesmus gracilis (Reisch) Korsikov (Chlorophyta) and Diaphanosoma biergein Korinek 1981 (Cladocera). Brazilian Journal of Biology, 68(4), 875-883. http://dx.doi.org/10.1590/S151969842008000400025

Toledo, J.D., Golez, M.S., Doi, M., \& Ohno, A. (1999). Use of copepod nauplii during early feeding stage of grouper Epinephelus coioides. Fisheries Science, 65(3), 390-397. http://dx.doi:10.2331/fishsci.65.390

Turner, J.T., Tester, P.A., \& Hettler, F. (1985). A laboratory study of predation on fish eggs and larvae by the copepods Anomalocera ornate and Centropages typicus. Marine Biology, 90:1-8.

Watanabe, T., Kitajima, C., \& Fujita, S. (1983). Nutritional values of live organisms used in Japan for mass propagation of fish: a review. Aquaculture, 34(1-2), 115 143. https://doi.org/10.1016/0044-8486(83)90296-X

Wiegand, M.D. (1996). Composition, accumulation and utilization of yolk lipids in teleost fish. Reviews in Fish Biology and Fisheries, 6(3), 259-286. https://doi.org/10.1007/BF00122583

Zeng, C., Shao, L., Ricketts, A., \& Moorhead, J. (2018). The importance of ciopepods as live feed for larval of the green mandarin fish Synchiropus splendidus. Aquaculture, 491, 65-71.

https://doi.org/10.1016/j.aquaculture.2018.03.011 